\title{
OS 50 ANOS DE ARQUIVOS DE NEUROPSIQUIATRIA
}

Com este Número 4, completa-se o Volume 50 de Arquivos de Neuro-Psiquiatria. De 1943 a 1992 foi mantida sua regularidade trimestral de modo absoluto, fato digno de ser realçado pela satisfação que traz. Com efeito, para poucos periódicos da área registra-se uma realização como essa. Nesses 50 anos nada foi alcançado com facilidade, tudo dependeu de trabalho e determinação.

Desde a criação da revista e até cessar sua vida, em 1986, o Dr. Oswaldo Lange "construiu" Arquivos de Neuro-Psiquiatria. Como seu Editor, buscou sempre aprimorar seu conteúdo, sua forma e sua divulgação. O entusiasmo contaminante do Editor fez dos que o cercavam seus colaboradores, muitos deles de sua própria família. Dentre estes, nesta oportunidade, é homenageada a memória de seu filho Sérgio Lange, cuja vida em 16 de julho de 1992 tam/bém cessou. Foi ele um dos émulos do estabelecimento da Associacão Arquivos de Neuro-Ps.quiatria Dr. Oswaldo Lange, em 1986, que gerenciou habilmente como Tesoureiro, tornando possível continuar a aprimorar a revista dentro dos sadios princípios do Editor Fundador.

Se, de início, Arquivos de Neuro-Psiqúiatria prestaram-se particularmente à divulgação da produção científica de certas regiões do Brasil, paulatinamente alcançou prestígio nacional. Este foi reconhecido em 1970 quando, em Porto Alegre, a Academia Brasileira de Neurologia, em sua assembléia geral, escolheu Arquivos Sé Neuro-Psiquiatria para ser seu periódico científico oficial. Especialistas de todo o Brasil continuaram a crer na revista, divulgando resultados de estudos inéditos, ampliando-se a qualidade do seu conteúdo científico. Essa qualidade, a categoria editorial e a regularidade na publicação permitiram que também se ampliasse o relevo internacional de Arquivos, atravessando fronteiras, vencendo barreiras como as de idioma. Com tudo isso, hoje, é também significativo o número de pesquisadores e profissionais de outros países que submetem à revista, para publicação, os resultados de sua produção científica e técnica.

A abrangência que Arquivos continua a conquistar resulta do trabalho conjunto dos integrantes da Associação, bem como da colaboração voluntária e muitas vezes anônima dos que a ela emprestam seus esforços. Junta-se ainda o papel dos assinantes: ao prestigiarem a revista, ativamente garantem a presença dela no meio em que atuam e a independência que mantém como veículo de expressão científica. Da interação de todos resulta a equipe de Arquivos de Neuro-Psiquiatria.

Não há manutenção de qualidade e nem de regularidade que, nos dias de hoje, deixem de obedecer ao princípio do trabalho em equipe. Isto é particularmente um fato quando o progresso constitui verdadeira meta. Em comunicação científica, esses aspectos ganham realce quer pela diversificação dos meios que lhe são próprios, quer pela diferenciação destes. Por outro lado, as ciências voltadas ao sistema nervoso cada vez mais também se diversificam e se diferenciam. Para elas cessaram os dias do enciclopedismo. Serve de exemplo a Neurologia, que hoje se unifica e se consolida na própria diferenciação de seus múltiplos campos, cada um deles verdadeira área de saber em si mesmo. Década do Cérebro é a que vivemos, e a crise no conceito de conhecimento constitui, na atualidade, um dos principais propósitos de estudo e de meta-análise na própria neurologia, asșim como na psiquiatria. Impõe-se, portanto, planificação e trabalho em equipe, entendida esta por atuação harmônica e programad̉a visando a uma dada finalidade. Este é o modo pelo qual são enfocados o desempenho e o papel de divulgação de Arquivos de Neuro-Psiquiatria.

Contundo, nada disso se faz na ^usencia de disciplina cercada de entusiasmo. É necessário a cada dia absorver novos recursos e ampliar horizontes para perseguir o propósito. Dessa forma, Arquivos apresenta caráter dinâmico, adotando continuamente novas normas recomendadas para a divulgação científica. Dentro dos limites de nossa realidade, são introduzidas modificaçôes para garantir a clareza do texto e para que estes sejam abrangentes quanto ao conteúdo, 
sintéticos quanto à forma, expressivos quanto ao que divulgam. Para catalogação, adotam-se palavras-chave; para divulgação, textos em português e em inglês; para aprimoramento na área, textos acerca de progressos e conceitos; para caracterizar a qualidade, a participação ativa de referees especializados na matéria.

Assim, hoje, Arquivos de Neuro-Psiquiatria, como periódico científico, é uma resposta dinâmica a necessidades de ensino, de pesquisa e de extensão de recursos à comunidade — tríade para a qual, mpitas vezes, não encontramos em nossas próprias universidades ambiente para seu pleno exercício, muito embora sejam a essência da universidade em si mesma. Para manter seu desem* penho em moldes universitários, em Arquivos tanto a forma como a disposição e a distribuição do conteúdo são contínua e dinamicamente modificadas. Os princípios, eles em si, não mudam. São uma realidade científica. E esta realidade não subsiste na esperança, mas no trabalho. Nesse contexto persiste, ao completar 50 anos, o objetivo de Arquivos de Neuro-Psiquiatria.

ANTONIO SFINA-FRANÇA

\section{AGRADECIMENTOS}

A Associação Arquivos de Neuro-Psiquiatria Dr. Oswaldo Lange, ao completar seu primeiro lustro, agradece aos que encaminharam contribuições científicas para publicação, aos encarregados pelo treinamento de especialistas por incluírem Arquivos entre as revistas cuja leitura recomendam, à, força recebida de muitas fontes. E impossível enumerar ou listar todas estas. É indispensável lembrar: a Academia Brasileira de Neurologia; os assinantes da revista e os colegas que nela divulgam sua atividade profissional; a parcela da indústria farmacêutica e a de produtores de material técnico que anunciam na revista; o Sr. Pedro C. de Barros Silva pelo esforço amigo e ativo; a Gráfica Sangirard nas pessoas de seus funcionários e colaboradores.

O Editor agradece, pelo desvelo, àquelas que avaliam seu trabalho editorial, garantindo a qualidade da revista.

A Junta Editorial de Arquivos de Neuro-Psiquiatria agradece aos colegas que aceitaram a incumbência de avaliar o conteúdo dos artigos submetidos para publicação durante este ano e que atuaram, assim, como referees ad hoc. Igualmente agradece aos autores, por aceitarem os pareceres acerca de seus textos dentro de construtivo e elevado espírito científico. Dos avaliadores a quem se agradece, são aqui lembrados:

Alberto Alain Gabbai

Alcides Codeceira Jr.

Amilton Antunes Barreira

Aron J. Diament

Benedicto Oscar Colli

Carlos A. Mantovani Guerreiro

Carmen L. Penteado Lancellotti

Egberto Reis Barbosa

Elza Dias Tosta

Fernando Menezes Braga

José Alberto Gonçalves da Silva

José Antonio Levy

José Antonio Livramento

José Geraldo Camargo Lima

José Luiz Dias Gherpelli

José Maurício Godoy

José Paulo Smith Nóbrega

José Píndaro Pereira Plese

Lígia M. Barbosa Coutinho

Lineu César Werneck

Lúcia Fontenelle

Luís dos Ramos Machado

Luiz Alberto Bacheschi
Luiz Augusto Franco de Andrade

Luiz Fernando Bleggi Torres

Marcos R. Gomes de Freitas

Marco Aurélio Lana Peixoto

Maria Valeriana L. de Moura Ribeiro

Mario Ferreira Coutinho

Mônica Santoro Haddad

Nelson Pires Ferreira

Nubor Orlando Facure

Orestes Barini

Osvaldo J.M. Nascimento

Osvaldo M. Takayanagui

Paulo César Trevisol Bittencourt

Ricardo de Oliveira Souza

Roberto Melaragno Filho

Ricardo Nitrini

Roque J. Balbo

Rubens José Gagliardi

Sebastião Eurico de Melo Souza

Sergio Augusto Pereira Novis

Sueli K. Nagahashi Marie

Walter Carlos Pereira

Wilson Luiz Sanvito 